\title{
REVITALIZING THE CENTRAL CORE OF AMINABAD, LUCKNOW
}

\author{
Akanchha Jain*
}

\begin{abstract}
A survey of the open spaces designated in Aminabad, Lucknow revealed an obvious lack of consideration towards the preservation of the public open spaces, and their physical/functional integration into the city, despite the high density of the urban fabric. With the increase in the pressure of the population in urban areas, there is a corresponding increase in encroachment on open spaces. If we analyze the situation of Aminabad, we realize that the decision taken long back, with emphasis on providing the automobile on the network of Aminabad, destroyed the convenience of the street. As a result of this decision, the street activity and visually stimulating streetscapes have broken down into loose incoherent sprawls. We may today rue the result, but better would be the attempts to correct some anomalies, however remote in character and intentions. This paper critically examines the present situation of Aminabad, Lucknow and a puts forward a brief proposal for revitalization of the market of Aminabad and is based on the survey done by students of M. Arch., Batch 2009, Integral University, Lucknow.
\end{abstract}

Keywords: Aminabad, Open Spaces, Market, Bazaar

\section{INTRODUCTION}

Urban planning is the art of making convivial places for people, which ensures successful urban environment. But with the impact of increased development in high density urban areas, the expression of our towns and cities has changed in the last few decades. Due to rapid urbanization, there is mounting pressure on the land, the recourse of outdoor recreation- shore line, green areas, open spaces, water, etc. which has diminished in the face of other demands. The outcome of this is disastrous. People find it difficult to keep a relation with nature.

Now a day's shopping is a bewildering experience. Aside from the completely westernized shopping megamalls which are popping up all over large cities, there are still thousands of stalls, street side vendors, underground markets and bazaars selling just about everything imaginable. Aminabad in Lucknow is one of these types of places, full of stores stocking brilliantly colorful clothes, textiles and other materials stacked from floor to ceiling, using every centimeter of space in each narrowly designed retail cubicle. Aminabad is a large bazaar located in the heart of Lucknow, in the Indian state of Uttar Pradesh. It came into prominence at the end of $18^{\text {th }}$ century. The construction of the Bazaar began in 1759, during the tenure of Shah Alam II. Shah Alam II also had an Imam Bargah, several other market places and a garden constructed at the same time. The entire area later came under the jurisdiction of Vazir Imdad Husain Khan, who got the title of 'Aminudaula' because of the development activities carried out under his tenure. Eventually the region came to be known as Aminabad, after the vazir's title. The modern day Aminabad Park was inaugurated by the Governor of Awadh in 1911.

The bazaar is famous for selling embroidered garments. fashion products, ornaments, jewelry, fashion garments, footwear and other such apparels. The bazaar is an intricate maze of narrow lanes. Over the years it has turned out to be one of the busiest zones in the city with problems of congestion and pollution.

\section{RESEARCH ASPECTS TO BE ADDRESSED}

Before a proposal can be made for sub head consumer behaviour, the revitalizaton and redevelopment of a market, the consumer behaviours, the impact of urban growth on the market and cultural and development issues need to be resarch, analysed and addressed. These aspects are briefly discussed here.

"It's really tough to know a customer just by taking a surface look or a surface descriptor such as male/female or age or ethnic group. To understand your customers' needs today, you really have to understand their lifestyles, opinions and attitudes.",

* Architect. Akanchha Jain, Sr. Lecturer, Amity University, Lucknow

1 David M. Szymanski, director of the center for retailing studies and professor of marketing at Texas A \& M University.

Journal of Research in Architecture and Planning: Vol. 15, 2013 (Second Issue) - Architecture, Urban Design \& Planning 


\begin{tabular}{|lll|}
\hline NATURE OF MOTIVE & \multicolumn{2}{c|}{ PURCHASE DECISION } \\
\hline 1. DESIRE FOR MONEY & $:$ & PREFER FOR BAR GAINING \\
2. VANITY & $:$ & GETTING COSTLY ITEMS, GOING TO \\
3. FEAR & $:$ & SHOWROOMS \\
4. PRIDE & $:$ & ATTRACTIVE SHOPS \\
5. FASHION & $:$ & RURAL PEOPLE MMTATE URBAN \\
6. POSSESSION & $:$ & PURCHASING ANTIQUES \\
7. HEALTH & $:$ & PROPER FOOD COURTS \\
8. COMFORT & $:$ & MOVING FOR SHOPPING MALLS \\
9. LOVE AND AFFECTION & $:$ & GOING WTTH FAMILY \\
\hline
\end{tabular}

Table 1: Relatonshp between motives and shopping behavour

Consumer behavior is broadly the study of individuals, or organizations and the processes consumers use to search, select, use and dispose products, services, experience or ideas to satisfy needs and its impact on the consumer and society.

\section{a) Importance of Study of Consumer Behavior:}

The reason to study consumer behavior is to understand the role it plays in the lives of humans.

\section{b) Impact of Urban Growth on Bazaars:}

\section{b.1. Social and economical issues:}

Public opinion has expressed a preference and a wish for arcades, market halls and even simple glazing covering existing streets.

\section{Buying an experience:}

The activity of shopping for this kind of public has moved on, from 1945 when it was mainly buying a product or a commodity, to the 1960s and 1970s when the focus was on service, to the latter part of the 1990s when shopping was about going out and obtaining an experience.

The challenge for designers is how to make the shopping environment a memorable experience. Shopping places will need to exploit this issue and make the visit memorable, even to the extent that the shopping trip becomes more important than the purchase.

\section{b.2. Cultural issues:}

Culture consists of traditional ideas and in particular the values, which are attached to the place. It includes:

- Knowledge,

- Belief,

- Art,

- Morale,

- Law,

- Customs,

- All other habits acquired by man as a member of society.

b.3. Development issues: Development issues must address:

- Site approach

- Land use pattern

- Traffic volume and character

- Public spaces

- Pedestrian movement

- Streetscape (hard \& soft) \& landscaping

- Architectural character 


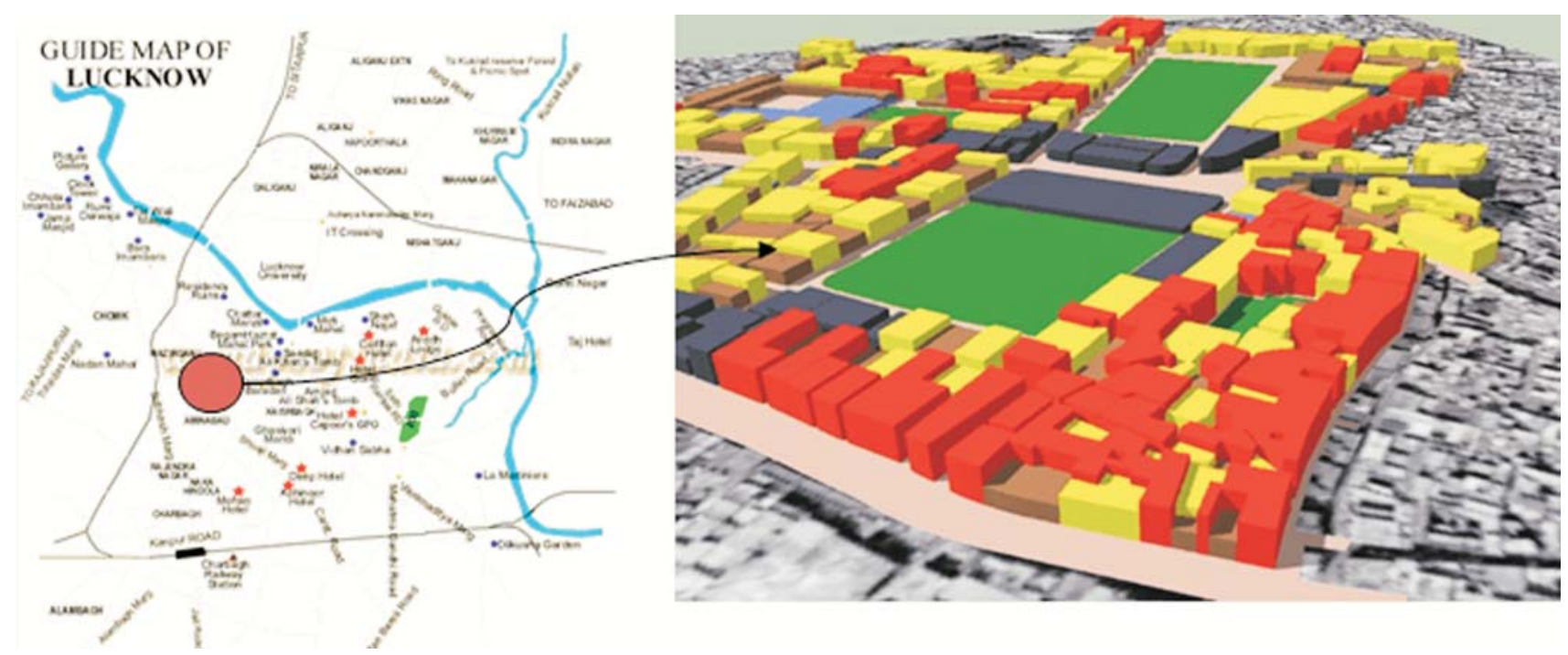

Figure 1: 3D view of Aminabad, Revitalization (to give new life or energy to somebody or something)

\section{EMERGENCE OF THE CHARACTER OF AMINABAD AS A CENTRAL BUSINESS DISTRICT}

\section{a) Social and Economical Issues:}

- Although shopping centers in the past have met many of these criteria, recent focus group research (in the survey done by students of M.Arch 2009 batch, Integral University Lucknow ) indicates that the public has a dislike for enclosed, internalized shopping environments and would prefer to go shopping in more natural environments where there is daylight, a feeling of contact with the outside and something unique or particular about that town or city. In Aminabad the general public coming for shopping is mostly of middle lower income group (see Figures 1 and 2).

- Without removing the shops or building structure, the central core of Aminabad should be used as the breathing space for people who are coming there.

- The place should be developed such as, that people of all classes can visit the place with interest.

\section{b) Cultural Issues:}

- There is no interaction space for the people at the time of festival who are visiting Aminabad. So the provision of a shopping court in the central core of Aminabad could cater to this need.

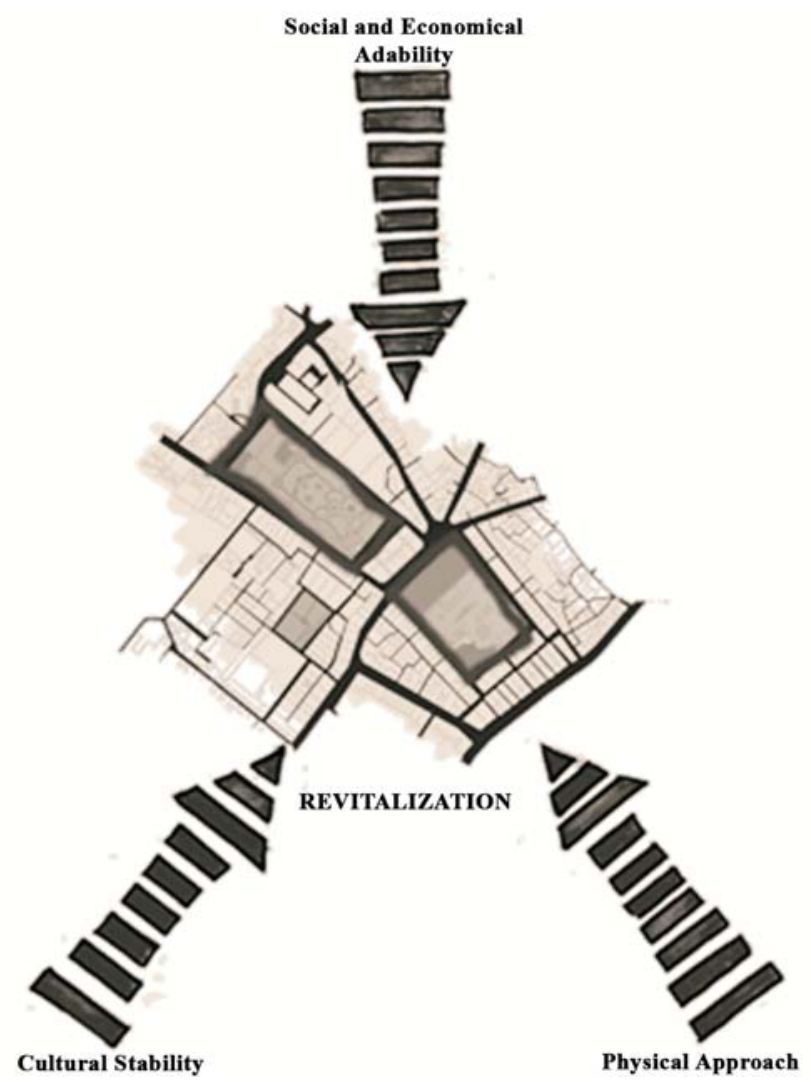

Figure 2: Identifying social, economic, cultural and physical issues facing Aminabad market 
- The encroachment along the roads should be removed to create the avenue and vista along the market.

\section{c) Development Issues:}

\section{c.1) Land-use}

- 29420 sq.m. built-up area has been demolished or needs to be maintained

- The findings of the survey show that more area is required for amenities and 2- $5 \%$ area of the locality requires to be redeveloped

\section{c.2) Architectural Character}

- There is no particular architectural character of Aminabad (45\% -Indo Islamic and Indo European. Rest of the character is mixed which includes new construction as well as renovation) (see Figure 3).

- About 5-10\% buildings have hoardings installed on them, which has spoiled their original character. Harmony in the streetscape is not maintained (see Figure 4).

\section{c.3) Transportation}

- Road congestion due to encroachment and lack of traffic management.

- Insufficient parking.

- No segregation of vehicular and pedestrian traffic

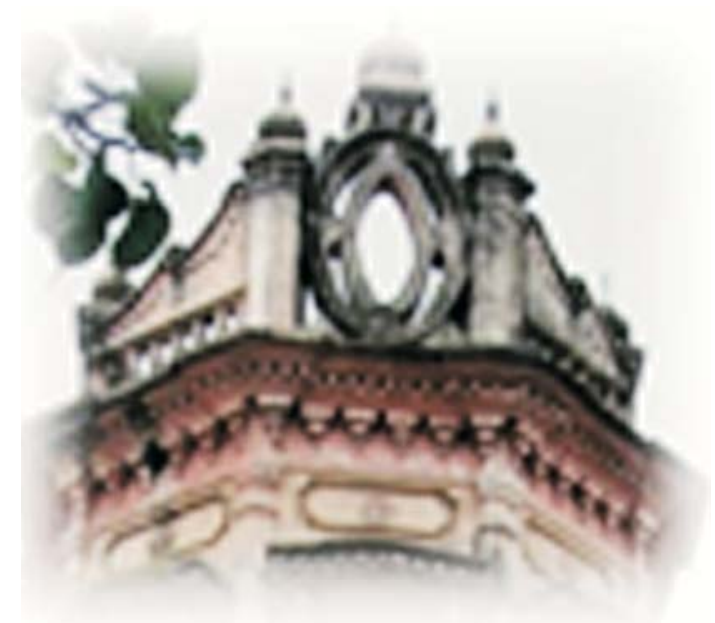

Figure 3: Architectural character of buildings in Aminabad

- Improper junctions.

- $\quad$ Lack of islands and roundabouts.

\section{OPEN SPACES}

With the densification of Aminabad, the open spaces are being encroached upon. Some of the issues with respect to open spaces are summarized here:

\section{a) Visibility:}

The Aminabad Park is surrounded by the market areas. The Aminabad Park consists of three sites, the Jadewala Park, the Hanuman Mandir Park and the Akadawala Park. These parks act as open spaces for the public within the congested
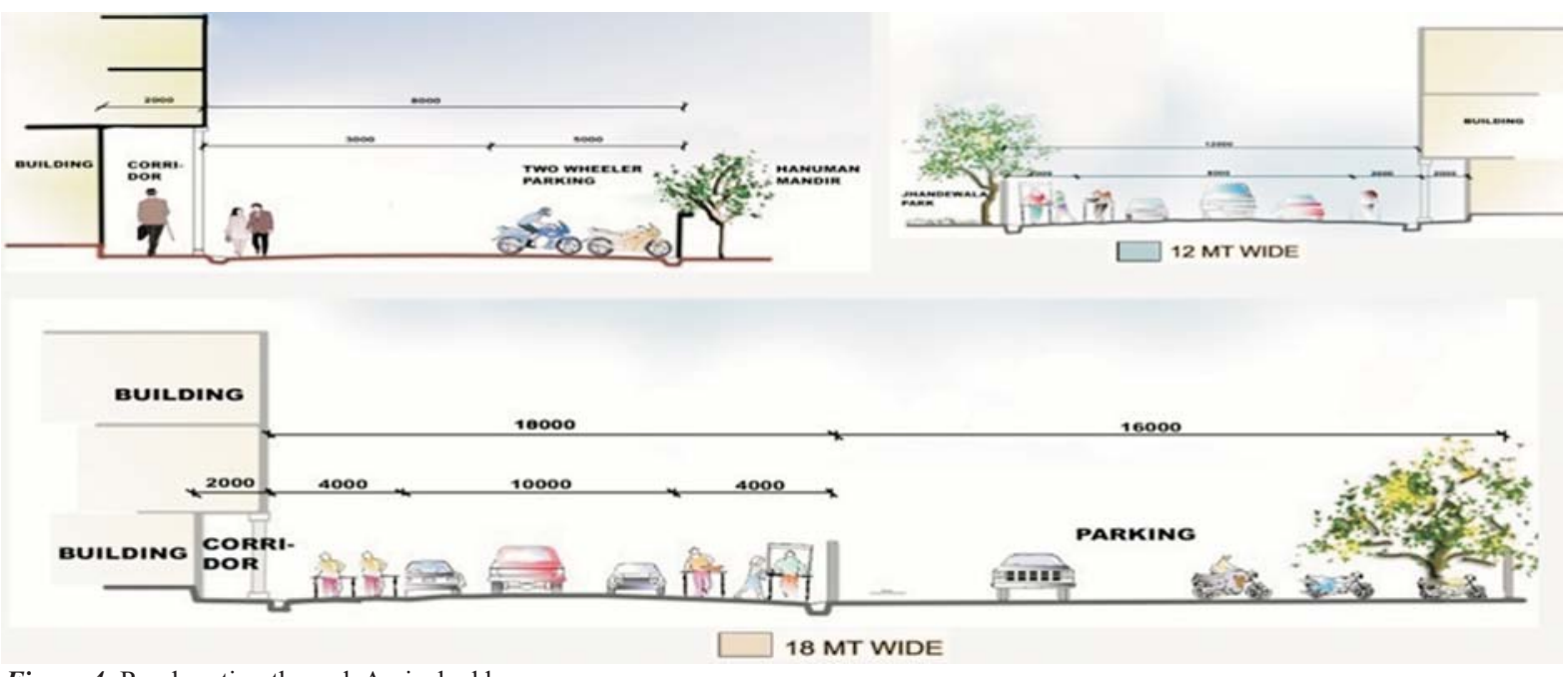

Figure 4: Road section through Aminabad bazaar 
market space of Aminabad. They have entries from three sides inviting people from all the directions (see Figure 5). These parks consists of religious buildings like the Mazar and other activities like electricity transformers, sulabh (social service organisation), underground and open areas for parking. These parks have features like statues, water body and sitting areas, giving it a lively environment (see Figures $6 \& 7$ ).
Sitting areas are also used for illegal activities in the parks. Due to the lack of maintenance the constructed areas of the parks are either damaged or taken away by people for personal use. Visual access of Aminabad is completely blocked off.

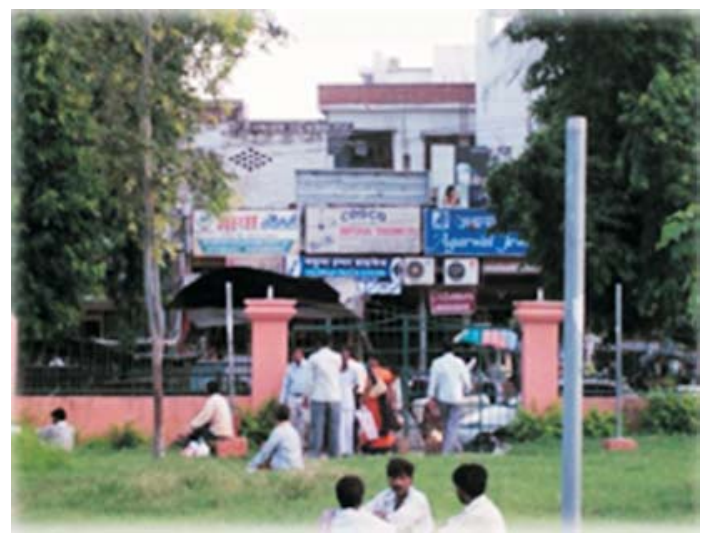

Figure 5: Entrance to open space in Aminabad Park

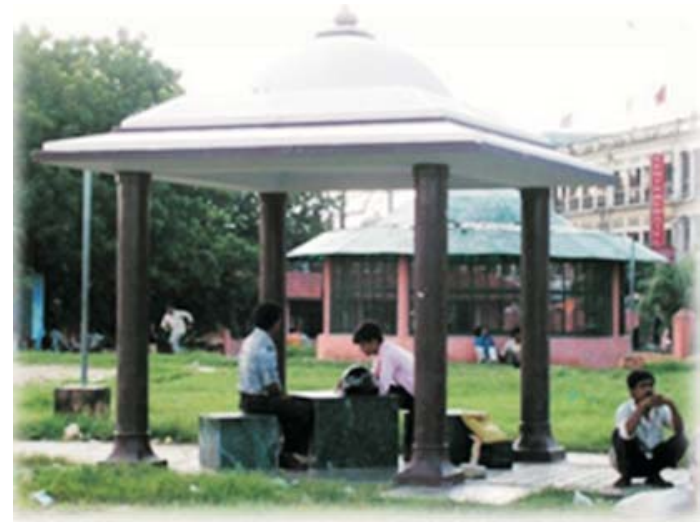

Figure 6: Kiosk in Aminabad Park

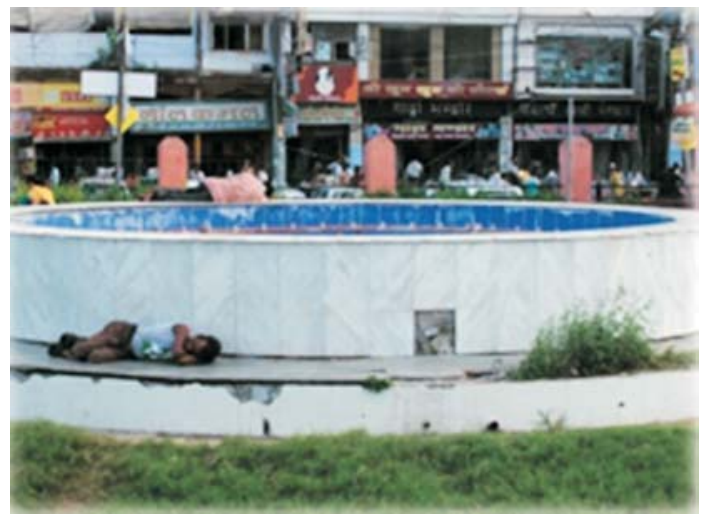

Figure 7: Fountain in Aminabad Park 


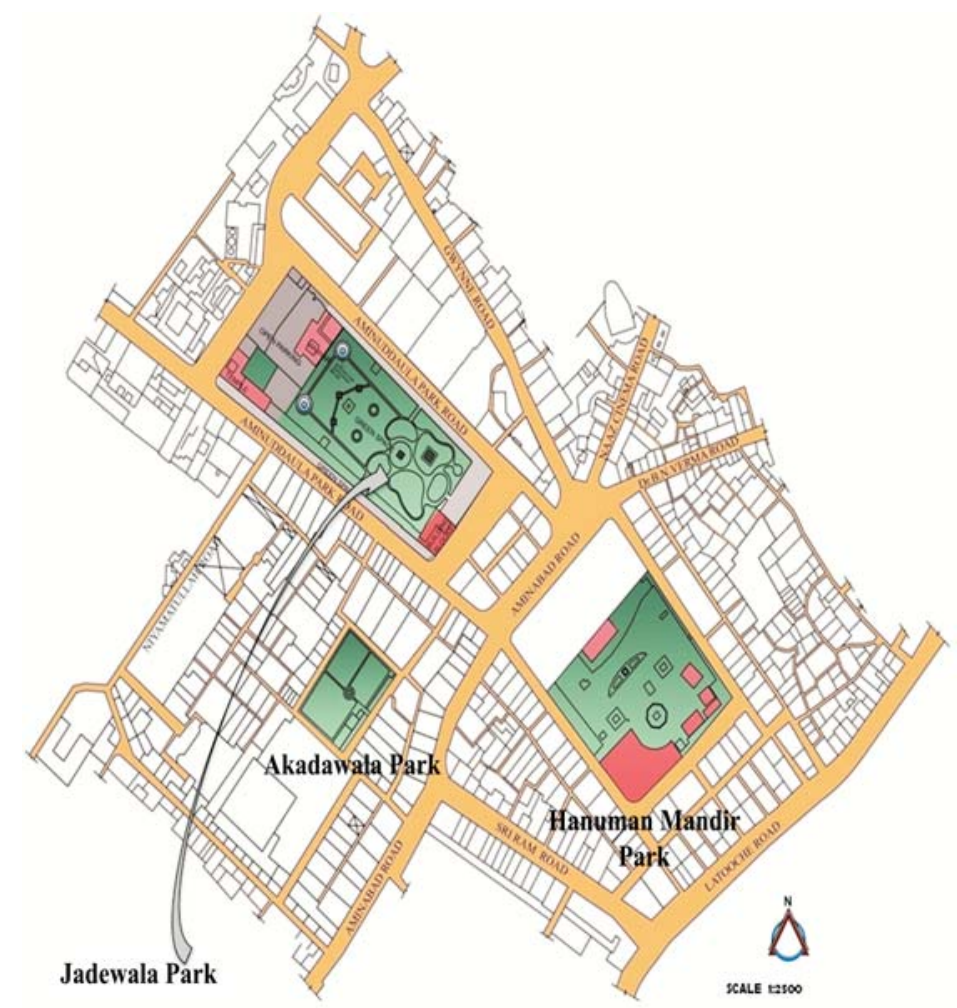

Figure 8: Green open space in Aminabad market

\section{Previous landscaped areas (see Figures 8 and 9):}

Jadewala Park:

27000 Sq.M

Hanuman Mandir Park: 18000 Sq.M.

Akada Wala Park: $6300 \mathrm{Sq} \cdot \mathrm{M}$.

\section{Current landscaped areas (see Figure 9):}

Jadewala Park:

23000 Sq.M

Hanuman Mandir Park:

Akada Wala Park:

\section{Sq.M}

5500 Sq.M.

The landscaped areas in the parks have reduced significantly over the years.

\section{b) Accessibility:}

Many open spaces in the public domain are completely inaccessible to the public. In the design proposal this issue is addressed by treating the Jadewala Park as an open space, housing the food court along with a pedestrian passageway that cuts across it.

\section{c) Encroachment:}

Encroachment can be seen throughout the roads of Aminabad. These encroachments are mainly long term. There are many encroachments in the open spaces, some of which, such as the maintenance sheds, may be essential for the upkeep of the space (see Figure 10).

Other facts that can be identified in the area are:

- Parking spaces are not adequate

- Encroachment causes the road width to reduce for traffic movement

- Better traffic circulation through the corridors is required

- The number of vendors on the sides of each road, calculated via the survey, points out the most encroached areas

- The research shows that the maximum number of vendors are at Hanuman Mandir Road, Bata Road, Aminabad Road, Pratap Market and little less congested is the Ganesh Ganj Road

- The research also shows that the venders are required to be shifted elsewhere, thereby providing free space 

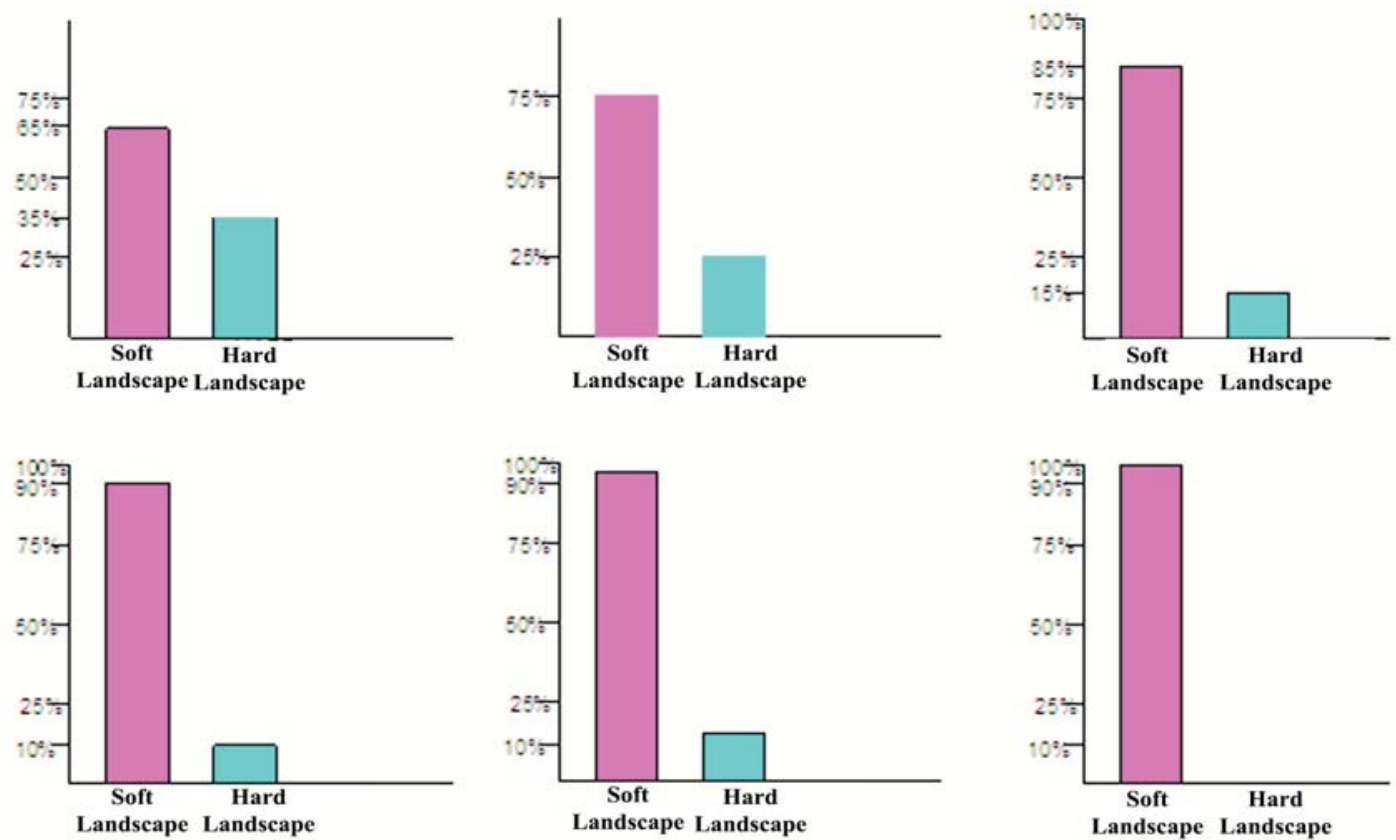

\section{Hanuman Mandir Park}

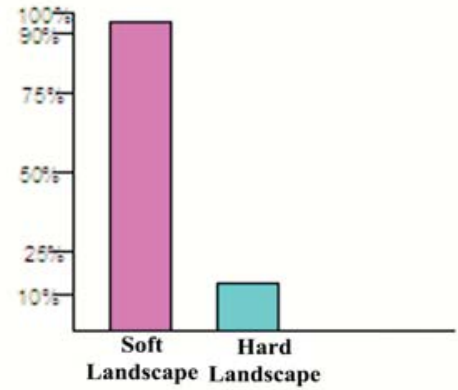

Jadewala Park

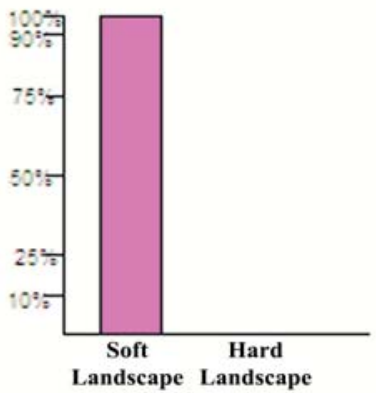

Akadawal Park

Figure 9: Bar graphs documenting current and previous \% of landscape in each park.

in the congested areas and clearing the roads for vehicular and pedestrian traffic

- The space required for the venders depends on the maximum type of sales on the road side, which needs to be accomodated adequately to avoid congestion

\section{CONCEPT}

Spaces and accessible spaces for the public can be used as significant points of orientation for users of the precinct, by providing visual orientation as well as pathways through it. They can be places where people would feel comfortable for stopping. People should be able to orient themselves through appropriate signage and maps placed nearby.

Aminabad Park has been treated as the Lucknow haat (a weekly market) as there is a requirement for a local market. In the design proposal it will be ensured that all open spaces are open to public from 6am to 9pm. Segregation of vehicular and pedestrian movements will also be ensured to safeguard the pedestrians. Controlling the vehicular movement in Aminabad will also minimize the traffic congestion (see Figure 11).

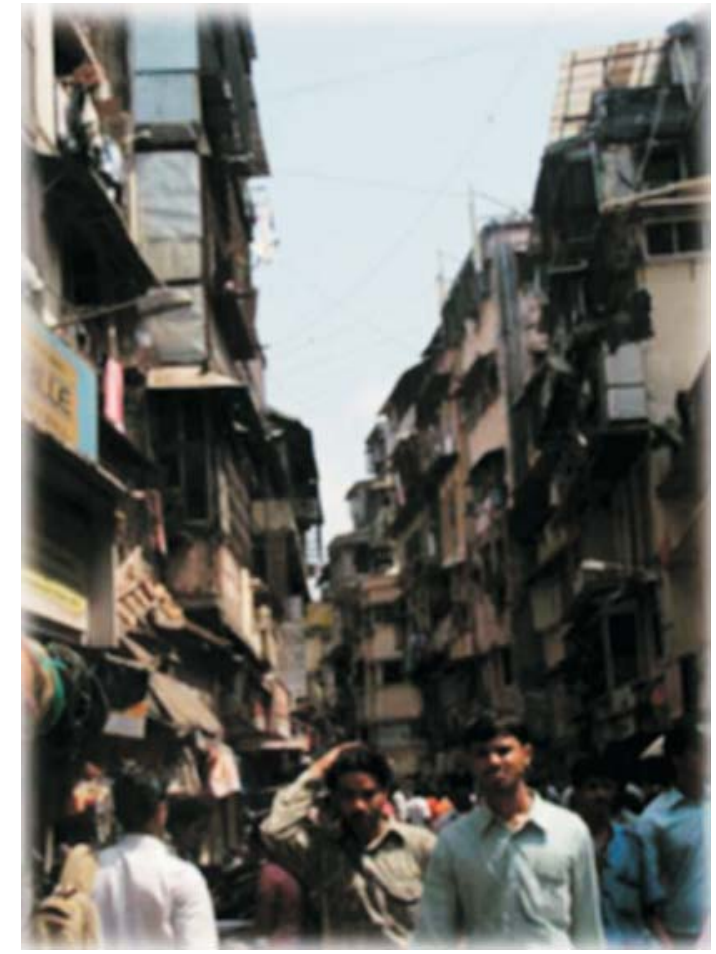

Figure 10: Congestion in market 


\section{CONCEPT}

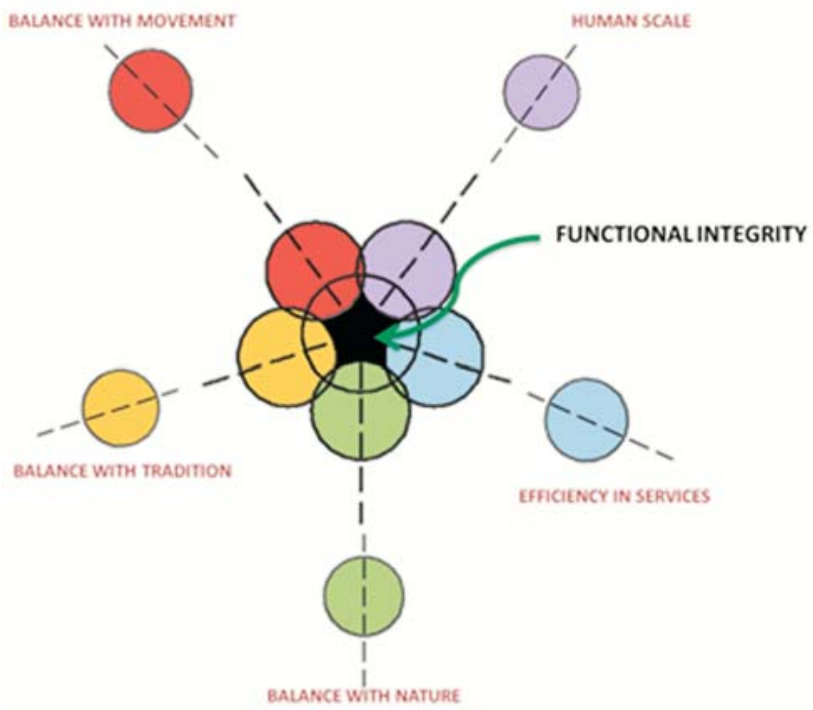

AN INTEGRATION OF FIVE AXIOMS

Figure 11: Formation of concept
Balance with nature: Providing open space, thereby conserving the elements that nurture the environment.

Balance with tradition: Architectural character of Aminabad is to be conserved. Bazaar concept is to be restored by providing haat. Location of haat should be such that architectural character can be emphasized.

Balance with movement: Control of the traffic congestion by proper segregation of pedestrian and vehicular movement, and provision of adequate parking spaces is proposed.

Human scale: The personal visibility of places is to be promoted.

Efficiency in services: Provision for rain water harvesting and using solar power as alternate energy source is also proposed.

\section{DESIGN PROPOSALS}

The following design proposals are made (see Figures 12 and 13).

\section{ZONING}

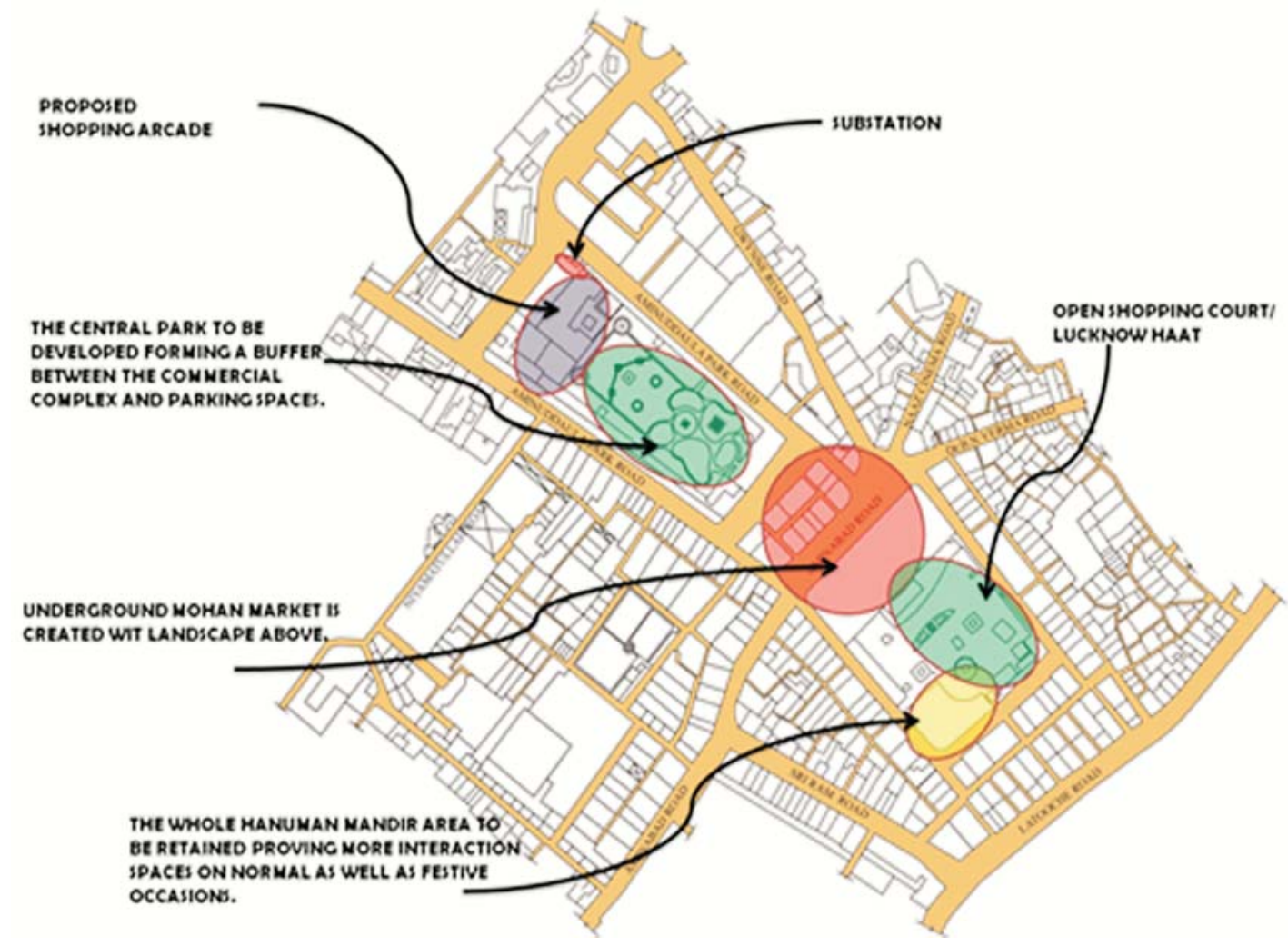

Figure 12: Proposed zoning plan 

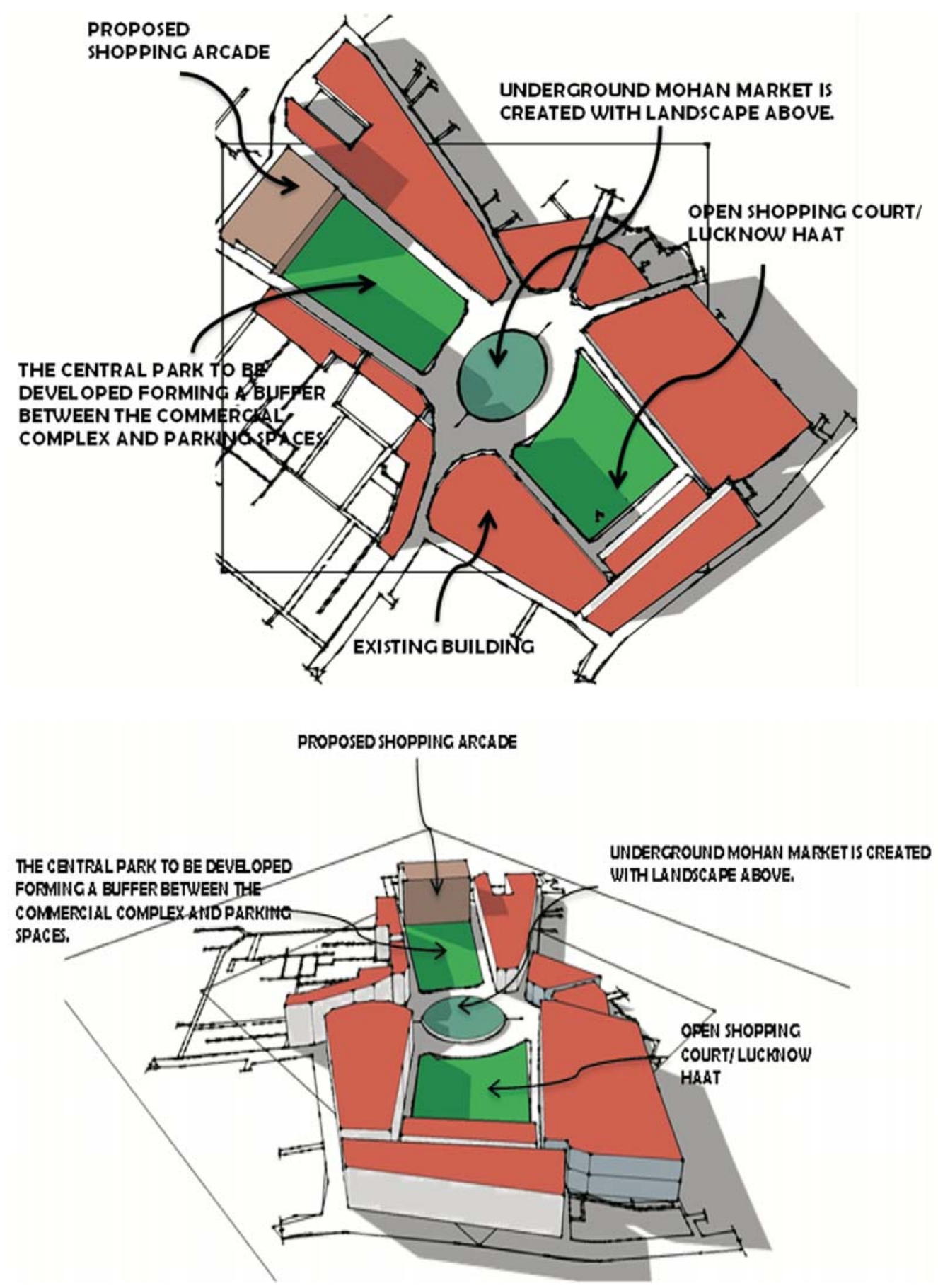

Figure 13: An overview of proposal for Aminabad 


\section{Traffic Regulation (Pedestrian \& Vehicular)}

1. Following junctions need to be redesigned:

- Junction between Latouche road and Sri Ram Road.

- Junction between Amin-Ud-Daula and Aminabad.

- Junction between Amin-Ud-Daula and taxi stand.

\section{Solution for Parking Problem}

It is proposed that basement parking should be provided in the Jhandewala park and Hanuman Mandir park, to meet the total number of parking requirement.

Along with more parking spaces for vehicles, cycle parking should also be provided.

\section{Land use pattern:}

1. To preserve the proposed hybrid character of the architecture in Aminabad a bye law should be framed for architectural control in Aminabad so that the future construction can follow the same typology.

2. Semi-basements should used for commercial purposes to relieve the market from over congestion.

3. Proposed areas to be divided as follows:

- A commercial centre having jewelry shops, big showrooms, banks, food court and two cinemas with a seating capacity of eighty people.

- Shopping complex: floor division for different usage

- Amenities: water, public toilets
- Parking to be provided: on ground parking, multilevel parking

- Encroachment shifted in the vendor market

- Weekly market proposed.

- Path along Jhandewala Park should be made one way.

\section{Architectural Control (Facade Improvement)}

1. Hybrid character should be maintained keeping in consideration a futuristic design philosophy outlining the vision for the area

2. The character of Aminabad should be retained by providing a blend of Islamic, European and Indian architectural features.

3. Use and choice of materials and colors should be as such that it looks balanced with the architectural features keeping in consideration the present and future scenario of Aminabad.

\section{CONCLUSION}

Aminabad is a historical neighbourhood of Delhi, which has lost its vibrancy and character because of congestion, pollution and un-controlled development.

All is however not lost and as demonstrated here, if an attempt is made towards understanding and analyzing the socio-econoic and cultural behaviour of shoppers of Aminabad, and the physical constraints in terms of densifiction and urban congestion, a design proposal can be put together which addresses the physical issues of the locality and thus result in its upgradation.

\section{REFERENCES}

Lucknow Master Plan 1919 \& 2021, LDA.

ITPI, Indian Institute of Town Planners

http://en.wikipedia.org/wiki/Aminabad,_Lucknow

http://www.ghumakkar.com/2008/04/01/by-the-lanes-of-aminabad-lucknow/

A survey done by students of M.Arch 2009 batch, Integral University Lucknow

DAVID M. SZYMANSKI, director of the center for retailing studies and professor of marketing at TEXAS A \& M University. 